\title{
Breast Cancer Immunohistochemistry Features Among Young Women in West Sumatera, Indonesia
}

\author{
Wirsma Arif Harahap ${ }^{1}$, Daan Khambri ${ }^{2}$, Ricvan Dana Nindrea ${ }^{3}$, Husna Yetti ${ }^{4}$ \\ \{wirsma@med.unand.ac.id ${ }^{1}$, daankhambri@fk.unand.ac.id ${ }^{2}$, ricvandana7@gmail.com³ \} \\ Division of Surgical Oncology, Dr. M.Djamil General Hospital/ Faculty of Medicine, Universitas \\ Andalas Padang, Indonesia ${ }^{1,2}$ \\ Department of Public Health and Community Medicine, Faculty of Medicine, Universitas Andalas \\ Padang, Indonesia ${ }^{3}$ \\ Department of Occupational and Environmental Health, Nagoya University Graduate School of \\ Medicine, Japan ${ }^{4}$
}

\begin{abstract}
Breast cancer incidence tends to increase, and it is suggested that it largely contributes to the rise of newly diagnosed cancers among young patients. The aim of this study to determine breast cancer immunohistochemistry features among young women in West Sumatera Indonesia. This study analyzed medical records of patients who belonged to the national health insurance program with breast cancer treatment. The study was conducted at the Dr. M. Djamil General Hospital Padang. The population in this study are all breast cancer patients (1st January 2005 to 19th October 2018). Amount of breast cancer among young women is 88 patients. Data were collected from medical records at the Division of Surgical Oncology Dr. M. Djamil General Hospital in Padang. Univariate analysis of the data in this study was used to find the disease-free and overall survival with subtype and stage and bivariate analysis was conducted on these survival statistics using the Kaplan-Meier method and log-rank test. Immunohistochemistry characteristics among young women with breast cancer using chi-square test. Data were analyzed by using STATA program. A two-tailed $P$-value of $<0.05$ was considered statistically significant. Data were analyzed using the Stata version 14.2 (Stata Corporation). The results showed LVI, stage, KI67, subtype, and status is associated with survival breast cancer among young women in West Sumatera, Indonesia $(\mathrm{p}<0.05)$. There is related breast cancer subtype significantly with the survival of breast cancer patients based on disease-free survival $(\mathrm{HR}=1.07$ (95\% CI 0.62-1.83)) with $\mathrm{p}$ log-rank test $\leq 0.05$. But overall survival did not result in a statistically significant $(\mathrm{HR}=0.99(95 \% \mathrm{CI} 0.58-1.70))$ with $\mathrm{p} \log$ rank test $>0.05$. There is related significantly breast cancer subtype with the survival of breast cancer patients based on disease-free survival $(\mathrm{HR}=1.07$ (95\% CI 0.62-1.83)) with $\mathrm{p}$ logrank test $\leq 0.05$. But overall survival did not result in a statistically significant (HR $=0.99$ (95\% CI 0.58-1.70)) with p log-rank test > 0.05. This analysis confirmed LVI, stage, KI67, subtype and status is associated with survival breast cancer among young women in West Sumatera, Indonesia.
\end{abstract}

Keywords: Breast Cancer, Immunohistochemistry, Young Women.

\section{Introduction}

Breast cancer has the highest cancer prevalence rates that cause the most common cancerrelated mortality among women in Indonesia. Breast cancer incidence tends to increase, and it 
is suggested that it largely contributes to the rise of newly diagnosed cancers among young patients [1],[2]. Prevalence of young patients accounts from 2-5\% of all breast cancer population [3],[4]. The early breast cancer is often characterized by the presence of a low histological differentiation, high mitotic activity, and frequent vascular wall invasion [5].

Many researchers pointed out the shorter three and five-years survival of young female patients in comparison with elderly females in premenopausal and postmenopausal age. This was the reason to include the age into the list of negative prognostic factors in breast cancer. Young female patients ( 35 years old and younger need more chemotherapy compared to the older patients according to recommendations of St Gallen consensus [6],[7].

There are many studies demonstrated that cancer patient's survival depends not only on the stage of the disease but also on the intrinsic biological factors, which predispose the characteristics of the tumors. The key neoplastic event is the genetic change, which leads to uncontrolled cell growth, loss of ability to differentiate and disturbance of apoptosis. The situation with the molecular-genetic features of the early breast cancer is not clear. The changes in estrogen receptor (ER), progesterone receptor (PR), HER-2/neu expression, the presence of apoptotic markers, changes of indices of proliferative activity are demonstrated for breast cancer patients of young age [8]. This study to determine breast cancer immunohistochemistry features among young women in West Sumatera, Indonesia.

\section{Methods and Materials}

\subsection{Study design and research sample}

This study analyzed medical records of patients who belonged to the national health insurance program with breast cancer treatment. The study was conducted at the Dr. M. Djamil General Hospital Padang. The population in this study are all breast cancer patients (1st January 2005 to 19th October 2018). Amount of breast cancer among young women is 88 patients.

\subsection{Operational definitions}

The subjects of this study are breast cancer in women (stage I-III). Immunohistochemistry characteristics: histologic type, grade, LVI, tumor size, subtype, N stage, stage, estrogen receptor, progesterone receptor, HER2, KI67, recurrence, and metastasis. Disease-free survival is determined from the length of time after completion of treatment until the onset of signs/ symptoms of cancer recurrence. Overall survival was calculated from diagnosis until the patient dies.

\subsection{Data collection technique}

Data were collected from medical records at the Division of Surgical Oncology Dr. M. Djamil General Hospital in Padang. This data was then coded and analyzed.

\subsection{Data analysis}

Univariate analysis of the data in this study was used to find the disease-free and overall survival with subtype and stage and bivariate analysis was conducted on these survival statistics using 
the Kaplan-Meier method and log-rank test. Immunohistochemistry features among young women with breast cancer using the chi-square test. Data were analyzed by using STATA program. A two-tailed $P$-value of $<0.05$ was considered statistically significant. Data were analyzed using the Stata version 14.2 (Stata Corporation).

\section{Results}

Distribution of age at diagnosis of breast cancer (Figure 1)

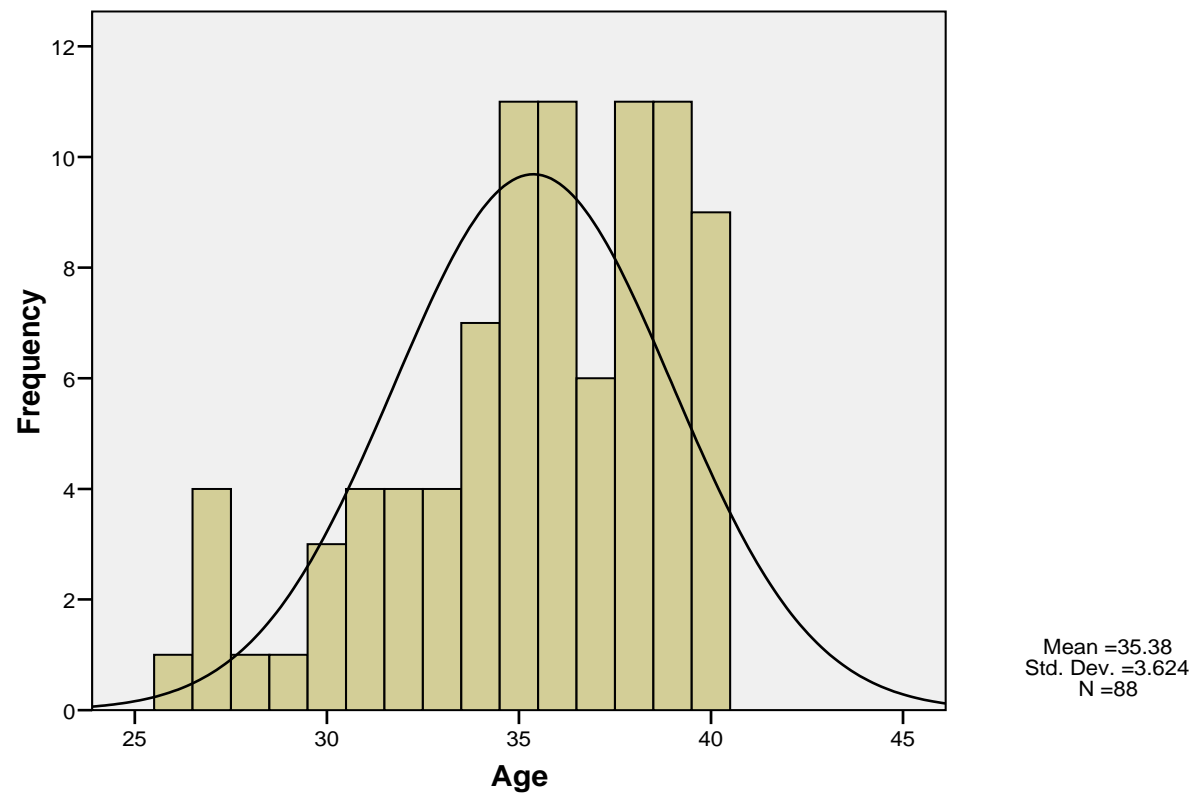

Fig. 1. Distribution of age at Diagnosis of Breast Cancer

The mean age in this study was $35.38 \pm 3.62$ years with the lowest age of 26 years and the highest age of 40 years. Baseline characteristics breast cancer among young women in West Sumatera, Indonesia (Table 1).

Table 1. Baseline characteristics breast cancer among young women in West Sumatera Indonesia.

\begin{tabular}{llll}
\hline Characteristics & $\begin{array}{l}\text { Time Periode } \\
2005-2014 \\
(\mathrm{n}=34)\end{array}$ & $\begin{array}{l}2015-2018 \\
(\mathrm{n}=54) \\
\mathrm{f}(\%)\end{array}$ & p-value \\
\hline $\begin{array}{l}\text { Age } \\
\text { ３0years }\end{array}$ & $2(5.9)$ & $8(14.8)$ & 0.305 \\
$\begin{array}{l}\text { 31-40 years } \\
\text { Histologic type }\end{array}$ & $32(94.1)$ & $46(85.2)$ & \\
$\begin{array}{l}\text { Ductal } \\
\text { Non ductal }\end{array}$ & $\begin{array}{l}26(76.5) \\
\text { Grade }\end{array}$ & $\begin{array}{l}46(85.2) \\
8(14.8)\end{array}$ & 0.454 \\
I & $3(8.8)$ & $1(1.9)$ & 0.171
\end{tabular}




\begin{tabular}{|c|c|c|c|}
\hline II & $28(82.4)$ & $51(94.4)$ & \\
\hline III & $3(8.8)$ & $2(3.7)$ & \\
\hline \multicolumn{4}{|l|}{ LVI } \\
\hline Negative & $34(100)$ & $41(75.9)$ & $0.005^{*}$ \\
\hline Positive & 0 & $13(24.1)$ & \\
\hline \multicolumn{4}{|l|}{ Tumor Size (T) } \\
\hline$<2.5 \mathrm{~cm}$ & $3(8.8)$ & $4(7.4)$ & 0.127 \\
\hline $2.5-5 \mathrm{~cm}$ & $9(26.5)$ & $13(24.1)$ & \\
\hline $5-10 \mathrm{~cm}$ & $16(47.1)$ & $35(64.8)$ & \\
\hline$>10 \mathrm{~cm}$ & $6(17.6)$ & $2(3.7)$ & \\
\hline \multicolumn{4}{|l|}{ N stage } \\
\hline No & $11(32.4)$ & $19(35.2)$ & 0.516 \\
\hline $\mathrm{N} 1$ & $13(38.2)$ & $18(33.3)$ & \\
\hline $\mathrm{N} 2$ & $9(26.5)$ & $11(20.4)$ & \\
\hline N3 & $1(2.9)$ & $6(11.1)$ & \\
\hline \multicolumn{4}{|l|}{ Stage } \\
\hline I-II & $11(32.4)$ & $18(33.3)$ & $0.034 *$ \\
\hline IIIA-IIIB & $19(55.9)$ & $36(66.7)$ & \\
\hline IV & $4(11.8)$ & 0 & \\
\hline \multicolumn{4}{|l|}{ Estrogen receptor } \\
\hline Negative & $18(52.9)$ & $37(68.5)$ & 0.214 \\
\hline Positive & $16(47.1)$ & $17(31.5)$ & \\
\hline \multicolumn{4}{|c|}{ Progesterone receptor } \\
\hline Negative & $19(55.9)$ & $30(55.6)$ & 1.000 \\
\hline Positive & $15(44.1)$ & $24(44.4)$ & \\
\hline \multicolumn{4}{|l|}{ HER-2 } \\
\hline Negative & $21(61.8)$ & $38(70.4)$ & 0.255 \\
\hline+ & $3(8.8)$ & $1(1.9)$ & \\
\hline++ & $1(2.9)$ & 0 & \\
\hline \multirow{2}{*}{\multicolumn{4}{|c|}{ KI67 }} \\
\hline & & & \\
\hline$<20 \%$ & $16(47.1)$ & $9(16.7)$ & $0.005^{*}$ \\
\hline$>20 \%$ & $18(52.9)$ & $45(83.3)$ & \\
\hline \multicolumn{4}{|l|}{ Subtype } \\
\hline Luminal A & $11(32.4)$ & $6(11.1)$ & $0.013 *$ \\
\hline Luminal B & $8(23.5)$ & $27(50.0)$ & \\
\hline HER2 & 7 (20.6) & $5(9.3)$ & \\
\hline TNBC & $8(23.5)$ & $16(29.6)$ & \\
\hline \multicolumn{4}{|l|}{ Recurrence } \\
\hline No recurrence & $21(61.8)$ & $44(81.5)$ & 0.062 \\
\hline Local recurrence & $6(17.6)$ & $7(13.0)$ & \\
\hline Metastasis & $7(20.6)$ & $3(5.6)$ & \\
\hline \multicolumn{4}{|l|}{ Status } \\
\hline Life & $26(76.5)$ & $51(94.4)$ & $0.020 *$ \\
\hline Death & $8(23.5)$ & $3(5.6)$ & \\
\hline
\end{tabular}

$* \mathrm{p}<0.05$, significance

Table 1 known age, histologic type, grade, tumor size, $\mathrm{N}$ stage, estrogen receptor, progesterone receptor, HER-2 and recurrence is not associated with survival breast cancer ( $>0.05)$. LVI, stage, KI67, subtype, and status is associated with survival breast cancer among young women in West Sumatera, Indonesia $(\mathrm{p}<0.05)$. The association of breast cancer subtype with the survival of breast cancer patients based on disease-free survival and overall survival (Table 2). 
Table 2. The association of breast cancer subtype with the survival of breast cancer patients based on disease-free survival and overall survival.

\begin{tabular}{llllllll}
\hline & Event & Censoring & $\begin{array}{l}\text { Median } \\
\text { follow } \\
\text { (months) }\end{array}$ & $\begin{array}{l}\text { Hazard Ratio } \\
\text { (95\% CI) }\end{array}$ & $\begin{array}{l}\text { P value } \\
\text { (Log-rank } \\
\text { test) }\end{array}$ \\
\hline $\begin{array}{l}\text { Disease } \\
\text { Free }\end{array}$ & Luminal A & 3 & 14 & $39(31-47)$ & 1.07 & $(0.62-$ & $0.050^{*}$ \\
Survival & & & & & $1.83)$ & & \\
& Luminal B & 2 & 33 & $29(22-36)$ & & & \\
& HER-2 & 3 & 9 & $38(19-56)$ & & \\
& TNBC & 3 & 21 & $31(20-41)$ & & \\
Overall & Luminal A & 3 & 14 & $48(40-56)$ & 0.99 & 0.973 \\
Survival & & & & & $(0.58-1.70)$ & \\
& Luminal B & 2 & 33 & $36(28-43)$ & & \\
& HER-2 & 3 & 9 & $44(27-62)$ & & \\
& TNBC & 3 & 21 & $42(29-54)$ & & \\
\hline
\end{tabular}

$* \mathrm{p}<0.05$, significance

Table 2 there is related breast cancer subtype significantly with the survival of breast cancer patients based on disease-free survival $(\mathrm{HR}=1.07$ (95\% CI 0.62-1.83)) with p log-rank test $\leq$ 0.05 . But overall survival did not result in a statistically significant (HR $=0.99$ (95\% CI 0.58 1.70)) with $\mathrm{p}$ log-rank test $>0.05$. The association of breast cancer subtype with the survival of breast cancer patients based on disease-free survival and overall survival by Kaplan-Meier (Figure 2).

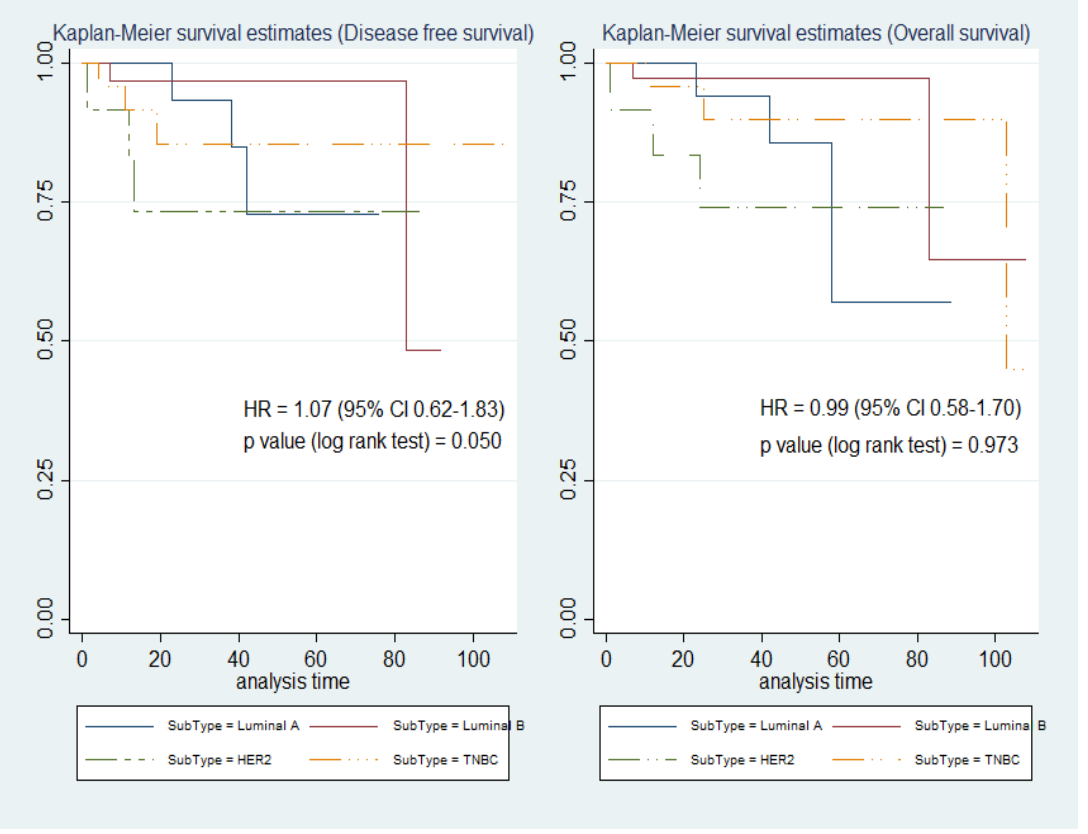

Fig. 2. The association of breast cancer subtype with the survival of breast cancer patients based on disease-free survival and overall survival. 
Table 3. The association of breast cancer stage with the survival of breast cancer patients based on diseasefree survival and overall survival.

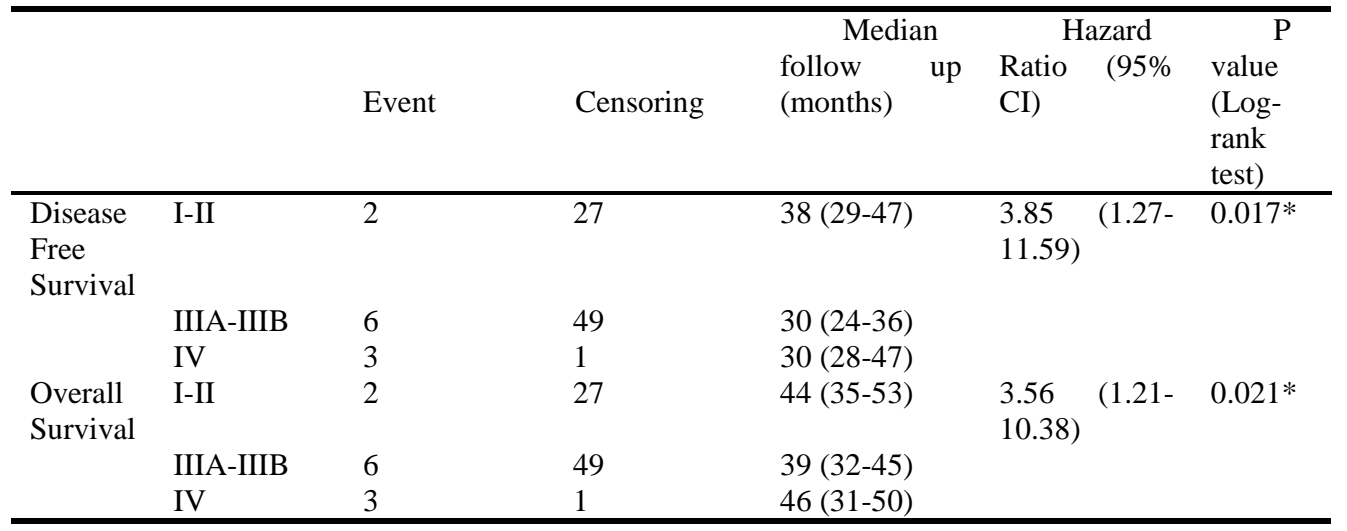

$* \mathrm{p}<0.05$, significance

Table 3 there is related breast cancer stage significantly with the survival of breast cancer patients based on disease-free survival $(\mathrm{HR}=3.85$ (95\% CI 1.27-11.59) ) and overall survival $(\mathrm{HR}=3.56$ (95\% CI 1.21-10.38) with $\mathrm{p}$ log-rank test $\leq 0.05$. The association of breast cancer stage with the survival of breast cancer patients based on disease-free survival and overall survival by Kaplan-Meier (Figure 3).

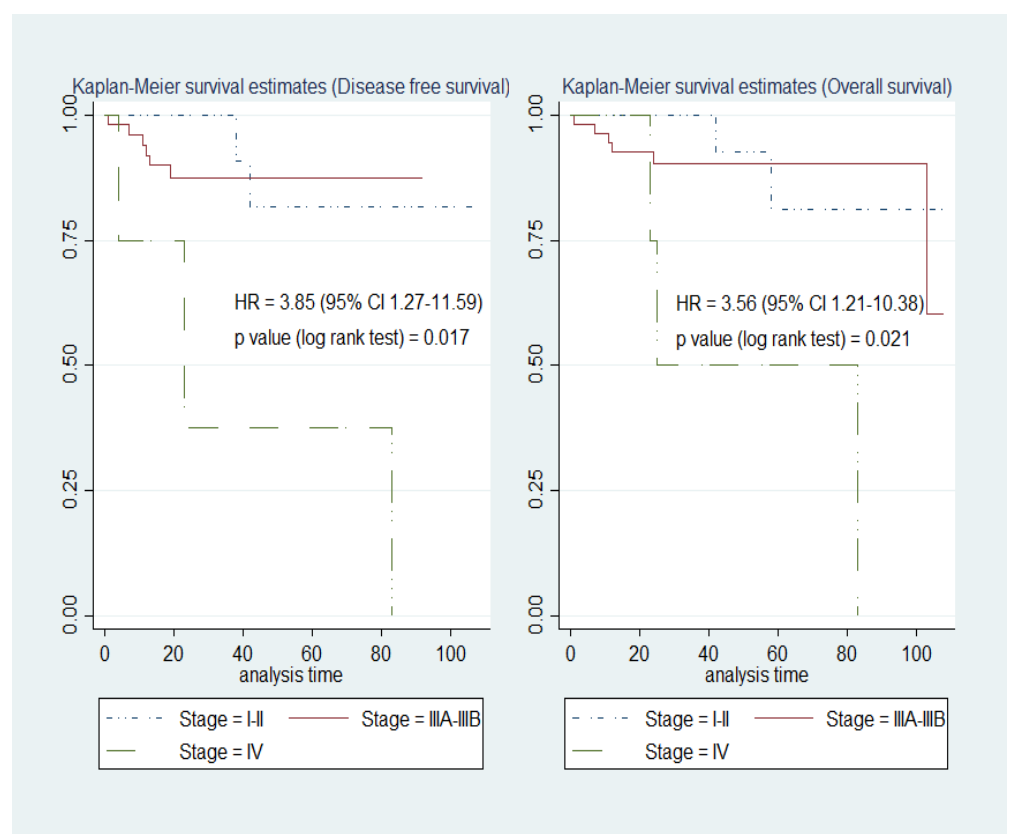

Fig. 3. The association of breast cancer stage with the survival of breast cancer patients based on disease free survival and overall survival. 


\section{Discussion}

The results showed LVI, stage, KI67, subtype, and status is associated with survival breast cancer among young women in West Sumatera, Indonesia $(\mathrm{p}<0.05)$. There is related breast cancer subtype significantly with the survival of breast cancer patients based on disease-free survival $(\mathrm{HR}=1.07$ (95\% CI 0.62-1.83)) with p log-rank test $\leq 0.05$. But overall survival did not result in a statistically significant $(\mathrm{HR}=0.99(95 \% \mathrm{CI} 0.58-1.70))$ with p log-rank test > 0.05 . There is related breast cancer subtype significantly with the survival of breast cancer patients based on disease-free survival $(\mathrm{HR}=1.07$ (95\% CI 0.62-1.83)) with p log-rank test $\leq$ 0.05 . But overall survival did not result in a statistically significant (HR $=0.99$ (95\% CI 0.58 1.70)) with $\mathrm{p}$ log-rank test $>0.05$.

Breast cancer in young age under 40 years old most of them were stage IIA, positive lymph node, tumor size larger than two $\mathrm{cm}$ and high grade [7]. It was higher than the results in breast cancer age 60 years old or more and similar with the study of Sundquist et al. (2002) who found tumors in young age to be larger with more lymph node involvement than in the elderly patients. In the next group, most of them were clinical stage IIIB, tumor size more than two $\mathrm{cm}$, positive ER, positive PR, positive p53 positive MIB-1, and positive c-erbB2 which were lower than breast cancer age below 40 years - old [9].

Breast cancer in people aged under 35 years old may have a worse prognosis than in elderly patients, usually with a high histological grade, extensive intraductal component, lymph vessel invasion and necrosis, more lymph node involvement, larger tumor size, negative estrogen receptor status, s-phase fraction abnormalities, and positive p53 expression. A study in France showed that breast cancer patients under the age of 40 had slightly worse overall survival compared with those with older age [7,10]. Although another study Bertheau et al. found no difference in the histological type of breast cancer between young and elderly patients [11].

A lot of young breast cancer patients received too aggressive therapy, whereas, some of them are not effectively treated and died prematurely. It is very important to have the objective molecular-biologic criteria, which could classify the aggressiveness of cancer in young patients [12]. Young breast cancer patients (35 years old and younger) need more chemotherapy compared to the older patients according to recommendations of St Gallen consensus [6],[7]. This analysis confirmed the survival of breast cancer patients is associated with subtype and stage among young women in West Sumatera, Indonesia. Previous studies show trastuzumab reduces recurrence by $36-52 \%$ and mortality by $33-37 \%$ when compared to placebo but the optimal duration of trastuzumab as adjuvant therapy is still a matter of debate. There is a consensus that there is little advantage of 2 years over one year but it has been unclear whether a therapy duration of 12 months is better than 6 months. This study found that the provision of 12 months provided better rates of disease-free survival, but not for overall survival. The fact that the patients in this study tended to be young and have cancer at an advanced local stage will have influenced these results [13].

In conclusion, our study found that breast cancer in young women showed more aggressive phenotype than elderly patients. This study suggests using relative survival the youngest group had the worst prognosis and the oldest group the best. In older women, the therapeutic strategy might have been more selective which leads to a better prognosis than in the younger age groups treated comparably.

Conflict of interest. The authors declare no conflict of interest. 
Acknowledgments. The authors would like to thank Syifa'u Warahmah for collecting data.

\section{References}

[1] Youlden DR, Cramb SM, Yip CH, Baade PD. Incidence and mortality of female breast cancer in the Asia-Pacific region. Cancer Biol Med. 2014; 11: 101-15.

[2] Nindrea RD, Aryandono T, Lazuardi L, Dwiprahasto I. Diagnostic Accuracy of Different Machine Learning Algorithms for Breast Cancer Risk Calculation: a Meta-Analysis. Asian Pac J Cancer Prev. 2018; 19(7):1747-1752

[3] Hankey BF, Miller B, Curtis R, Kosary C. Trends in breast cancer in younger women in contrast to older women. J Natl Cancer Inst Monogr 1994; 16: 7-14.

[4] Brinton LA, Sherman ME, Carreon JD, Anderson WF. Recent trends in breast cancer among younger women in the United States. J Natl Cancer Inst. 2008; 100(22): 1643-8.

[5] Hartley MC, McKinley BP, Rogers EA, Kalbaugh CA, Messich HS, Blackhurst DW, et al. Differential expression of prognostic factors and effect on survival in young $(<$ or $=40)$ breast cancer patients; a case-control study. Am Surg 2006; 72(12): 1189-94.

[6] Sidoni A, Cavaliere A, Bellezza A, Scheibel M, Bucciarelli E. Breast cancer in young women: clinicopathological features and biological specificity. Breast. 2003; 12(4): 247-50

[7] Aryandono T, Harijadi, Soeripto. Breast cancer in young women: prognostic and clinicopathological features. Asian Pac J Cancer Prev. 2006; 7: 451-4.

[8] Musolino A, Bella M, Bortesi B, Michiara M, Naldi N, Zanelli P, et al. BRCA mutation, molecular markers and clinical variables in early-onset breast cancer: a population-based study. Breast. 2007; 16(3): 280-92.

[9] Sundquist M, Thorestenson S, Brenden L, Wingren S, Nordenskjold B. Incidence and prognosis in early onset breast cancer. The Breast. 2001; 11: 30-5.

[10] Grosclaude P, Colonna M, Hedelin G, Tretarre B, Arveux P, Lesec'h JM, Raverdy N, et al. Survival of women with breast cancer in France: variation with age, stage and treatment. Breast Cancer Res and Treat. 2001; 70(2):137-43.

[11] Bertheau P, Steinberg SM, Merino MJ. C-erbB-2, p53, and nm23 gene product expression in breast cancer in young women : immunohistochemical analysis and clinicopathologic correlation. Hum Pathol. 1998; 29: 323-9.

[12] Frank TS, Deffenbaugh AM, Reid JE, Hullick M, Ward BE, Lingenfelter B, et al. Clinical characteristics of individuals with germline mutations in BRCA1 and BRCA2: analysis of 10,000 individuals. J Clin Oncol. 2002; 20: 1480-90.

[13] Harahap WA, Ramadhan, Khambri D, Haryono S, Nindrea RD. Outcomes of trastuzumab therapy for 6 and 12 months in Indonesian National Health Insurance System Clients with operable HER2-positive breast cancer. Asian Pac J Cancer Prev. 2017; 18(4): 1151-6. 